\title{
OPTIMIZED DESIGN AND ANALYSIS OF OFFSHORE BEIDOU MARITIME FOUNDATION REINFORCEMENT SYSTEM PSEUDOLITE RANGING-CODES
}

\author{
Deliang Su, Ph. D., \\ Anan Zhou, M.S., \\ School of Information Engineering, Wuhan University of Technology, Wuhan, 430074, China \\ Zilin Zhou, E. E. M.S., \\ China Transport Telecommunications and Information Center, Beijing, 100011, China \\ Wei Chen, Prof. Dr., \\ School of Automation, Wuhan University of Technology, Wuhan, 430074, China
}

\begin{abstract}
Under the bad sea conditions and weak Beidou navigation signal environment, it is difficult to locate the ship on the sea, and the Beidou navigation system can't work well. Beidou pseudolite system can improve the performance of Beidou navigation system as a navigation signal transmitter fixed on the ground, the signal of which can improve satellite positioning constellation structure, and improve the system availability reliability and precision. In order to ensure the interoperability and non-correlation of the Beidou pseudolite and the Beidou navigation system, the pseudolite ranging-codes should be selected in the same code space of the satellite ranging-codes and the residual pseudo random code generated by the 2 taps design scheme does not satisfy the performance requirements of the ranging-codes. To solve this issue, a combined design scheme with 3 taps is proposed, and 12 kinds of pseudolite ranging-codes are optimally selected according to the optimum design parameters of ranging-codes. The waveform and correlation of the selected pseudolite ranging-codes are analyzed by MATLAB, the acquisition simulation is carried out by using the new pseudolite ranging-codes. The experimental results show that the new 3-taps based ranging codes design scheme behaves a good balance, correlation and spectral characteristics.
\end{abstract}

Keywords: Beidou pseudolite; Ranging-codes; Optimized; 3-taps

\section{INTRODUCTION}

The Global Navigation Satellite System (GNSS) is widely used in land, sea, air and space of various military and civilian fields, to provide global, all-weather, continuous high precision timing and real-time location, which has become one of the important national infrastructure in information age [1]. It is more and more important to establish an independent global navigation satellite system for the construction of national defense, economic development, aerospace industry and the establishment of standard time and space system [2]. The navigation signal is one of the important parts of the satellite navigation system, relate to the basic functions of the system positioning, time service and velocity measurement, and the key performance and indicators of the accuracy, compatibility and interoperability, confidentiality, anti-interference ability
[3-7]. The ranging code is a major component of satellite navigation signals, which plays an important role in the satellite navigation signals, the performance of the ranging code is directly related to the performance of acquisition, tracking and demodulation, anti-jamming and secrecy etc. [8].

Beidou satellite navigation system (BD) is Chinese independent research and development of the global satellite navigation system, after more than 10 years of development, has been upgraded to the second generation [9]. So far, the system has been covering the entire Asia Pacific region, providing navigation, timing and short message communication services [10]. In recent years, Beidou navigation satellite system is playing an increasingly important role in transportation, mapping, communications, navigation, defense and so on. However, BD are also facing many problems: First, in some cities with high buildings, 
or environments with mountains and other terrain valleys, pseudo range positioning accuracy is relatively low. Especially at present the number of satellites in the Bedouin system is not enough. Satellites being blocked have resulted in lowaccuracy of pseudo-range positioning, or even it is not able to locate [11]; second, due to the effects of the atmosphere and multi-path transmission, when the quality of the satellite data received by the receiver is not high, BD pseudo range positioning effect is not unsatisfactory. In this case, under the condition of weak signal, there is a problem that the Beidou receiver even can't acquire the navigation signal; Beidou pseudolite system provides a solution to this problem [12]. Beidou pseudolite can be seen as a Beidou navigation signals transmitter which is fixed on the ground, the signal of it can improve satellite positioning constellation structure, and improve the availability of the system, reliability and precision [13]. As the ground navigation signal transmitting device, Beidou pseudolite system can expand the signal coverage of the Beidou satellite navigation system, improve the positioning accuracy of the navigation system, enhance navigation service availability and integrity [14-15]. In the pseudo satellite auxiliary positioning, in order to ensure maximum compatibility of the Beidou satellite system, it requires that pseudolite and Beidou satellite ranging-codes belong to the same code space but different phase to meet the requirements of CDMA technology. According to the contents of Beidou System spatial signal interface control [16], in the design of the same ranging-codes generator, apart from the 37 ranging codes which have been used by Beidou satellite, the remaining $18\left(\mathrm{C}_{11}^{2}-37=18\right)$ types of combinations are unbalanced codes, and they do not satisfy the design requirements of navigation signal ranging-codes. According to the design requirements of pseudo satellite ranging-codes, the new tap design scheme is proposed in the paper, and 12 kinds of optimal performance of pseudolite ranging-codes were selected, in order to satisfy the needs of the pseudo satellite system.

\section{THE DESIGN OF PSEUDOLITE RANGING-CODES}

Beidou pseudolite ranging-codes consist of pseudorandom codes. In order to ensure interoperability with the Beidou system, the structure of pseudolite ranging-codes is used isomorphic mechanism with Beidou satellites of which the compatibility is the best. Pseudolite ranging-codes and satellite ranging-codes belong to the same code space, and to ensure non-correlation, the pseudolite ranging-codes should be selected from the codes which have not been used by Beidou satellite system. According to the Beidou ICD file, the Beidou satellite B1I signal ranging-codes (CB1I) generator mainly uses the G2 shift register to select different taps to achieve different phase offset. Given the design idea of the recent isomorphism principle, the pseudo satellite rangingcodes should be design from the surplus Beidou satellite ranging-codes which are produced by the 2 tap combination.
The G2 shift register series is known to be $\mathrm{n}=11$ which can produce 2047 kinds of random codes. After excluding itself, G2 sequence cycle is 2046 which means that G2i phase shifts is 2046. The 2046 possible choices phase shifts can be expressed by the formula (1).

$$
\mathrm{C}_{11}^{1}+\mathrm{C}_{11}^{2}+\mathrm{C}_{11}^{3}+\mathrm{C}_{11}^{4}+\ldots+\mathrm{C}_{11}^{10}=2046
$$

The 37 kinds of Beidou satellite pseudo random codes which are generated by 2 -tap combination are selected as the satellite navigation signal ranging-codes. The unbalance values of the remaining $18 \mathrm{kinds}$ of pseudo random codes generated by 2 -tap combination are shown in Table 1 . From the balance values of the pseudo-random codes in the table, it can be seen that the generated pseudo-random codes don't belong to the balanced codes, which don't satisfy the requirements of the ranging-codes, so it can't be used as the pseudolite ranging-codes.

According to the Formula (1), the 3-taps method can be selected to realize the phase shift. The principle workflow of the G2 shift register 3-taps combination is shown in Figure 1.

$$
\begin{gathered}
G 1(x)=1+x+x^{7}+x^{8}+x^{9}+x^{10}+x^{11} \\
G 2(x)=1+x+x^{2}+x^{3}+x^{4}+x^{5}+x^{8}+x^{9}+x^{11}
\end{gathered}
$$

In the formula, both the initial phases of $\mathrm{G} 1$ and $\mathrm{G} 2$ are: 01010101010 .

\section{OPTIMIZATION OF THE PSEUDOLITE SIGNAL RANGING-CODES}

The 3-tap combination of $\mathrm{G} 2$ sequence can produce $165\left(C_{11}^{3}=165\right)$ offset phases, and 12 kinds of combinations which have the optimal performance are selected according to the corresponding evaluation indicators of the rangingcodes. The selection standards are evaluated according to the following rules:

\section{BALANCE VALUE}

The Gold code which is composed of the M sequences is divided into the balanced code and the unbalanced code. The balanced code has better spectrum performance and good effects on carrier's suppression. If unit of the carrier's suppression is $\mathrm{dB}$, the balanced code will be more than $50 \%$ the unbalanced codes. For the Gold code, the balanced code is obtained when it conforms to the Formula (4).

$$
\left|\sum_{i=0}^{N} \operatorname{Gold}(i)\right|=1
$$

In the Formula (4), the Gold(i) shows the values of the $\mathrm{i}^{\text {th }}$ chip in the Gold code. 


\section{CORRELATION EVALUATION}

For the navigation system, the selected spreading code sequence of the navigation signal must utilize good correlations. According to the definition of the correlation, in the autocorrelation operation, the main lobe for the ideal normalized value of sequence should be 1 , while on the side lobe the values are all zero; in the cross-correlation operation, on the side lobe a pair of ideal values of sequences are all zero. But there exists so idealized sequence in the actual situation, so the better performance of spreading codes should be chosen. The correlation can be evaluated according to the following parameters:

1) Maximum autocorrelation side-lobe value. This parameter can be expressed by the Formula (5).

$$
\operatorname{auto}(a ; \tau)=\sum_{i=0}^{N} a_{i} a_{i+\tau}
$$

The smaller the better the results will be. When the value is smaller, it reflects that the spreading codes of the main-lobe have larger value in the autocorrelation, its autocorrelation performance is better.

2) Maximum cross-correlation side-lobe value. This value can be expressed by the Formula (6).

$$
\operatorname{auto}(\mathrm{a} ; \mathrm{b} ; \tau)=\sum_{i=0}^{N} a_{i} b_{i+\tau}
$$

Tab. 1. The remaining 18 kinds of 2 - tap unbalanced combination parameters

\begin{tabular}{|c|c|c|c|c|c|}
\hline $\begin{array}{c}\text { Ranging } \\
\text { codes number }\end{array}$ & G2 taps selection & $\begin{array}{c}\text { Unbalance } \\
\text { values }\end{array}$ & $\begin{array}{c}\text { Ranging } \\
\text { codes number }\end{array}$ & $\begin{array}{c}\text { G2 taps } \\
\text { selection }\end{array}$ & $\begin{array}{c}\text { Unbalance } \\
\text { values }\end{array}$ \\
\hline 38 & $1 \oplus 2$ & -63 & 47 & $2 \oplus 11$ & -63 \\
\hline 39 & $1 \oplus 7$ & -63 & 48 & $3 \oplus 7$ & 65 \\
\hline 40 & $2 \oplus 3$ & 65 & 49 & $4 \oplus 7$ & 65 \\
\hline 41 & $2 \oplus 4$ & -63 & 50 & $5 \oplus 7$ & 65 \\
\hline 42 & $2 \oplus 5$ & -63 & 51 & $6 \oplus 7$ & -63 \\
\hline 43 & $2 \oplus 6$ & 65 & 52 & $7 \oplus 8$ & 65 \\
\hline 44 & $2 \oplus 8$ & -63 & 53 & $7 \oplus 9$ & -63 \\
\hline 45 & $2 \oplus 9$ & -63 & 54 & $7 \oplus 10$ & 65 \\
\hline 46 & $2 \oplus 10$ & -63 & 55 & $7 \oplus 11$ & 65 \\
\hline
\end{tabular}

The smaller of the value, the better the result will be. When the value of the parameter is smaller, it reflects that the cross-correlation value of the spreading code with the other spreading code is smaller, and the value of the crosscorrelation interference generated is smaller.

3) Reciprocal of the linear autocorrelation quality Factor. It can be expressed by the Formula (7).

$$
M F^{\mathrm{L}}=\frac{1}{\sum_{i=0}\left|\bar{R}_{c}(l)\right|^{2}}
$$

In the formula, the $\bar{R}_{c}(l)$ is the autocorrelation sidelobe value, the $\sum_{i=0}\left|\bar{R}_{c}(l)\right|^{2}$ is the square sum of the linear autocorrelation side-lobe which can directly reflect the statistical characteristics of the interference between the spread codes. Therefore, it is more intuitive to use the reciprocal of the linear autocorrelation quality factor as an evaluation index.

4) Reciprocal of the linear cross-correlation quality Factor. It can be expressed by the Formula (8).

$$
C M F^{\mathrm{L}}=\frac{1}{\sum_{i=-N-1}^{N-1}\left|\bar{R}_{\mathrm{clc} 2}(l)\right|^{2}}
$$

In the formula, the $\left|\bar{R}_{\mathrm{c} 1 \mathrm{c} 2}(l)\right|$ is the linear cross-correlation side-lobe value. As the same reason mentioned above, the reciprocal of the linear cross-correlation quality factor is used as an evaluation index.

\section{MAXIMUM SPECTRUM AMPLITUDE VALUE}

Another important designing indicator of the Beidou pseudolite ranging- codes are maximum spectral amplitude value, which can be expressed by Formula (9).

$$
\text { Spec }=\max |F T(c(n))|
$$

In the formula, the $F T(c(n))$ is the Fourier transform of the $c(n)$ and the value of the Spec has direct impacts on the ability of anti-narrowband interference on pseudo codes. Since the pseudo code signal has a fixed transmit power, if the Spec become larger, the influence of the narrow-band interference on the pseudo-code will significantly increase rules, and otherwise, it will decrease. Therefore, when it needs to select the spreading code, it is expected to select the pseudo code which has the largest spectrum amplitude, to increase its anti-interference ability on the narrow band and to ensure the normal communication of the signals.

According to the selection standards of ranging-codes, the optimal selection steps of the Beidou pseudolite rangingcodes are shown as follows:

Firstly, the G2 sequence 3 taps combination has totally 165 kinds of offset phases, all balanced codes are selected from the 165 kinds of codes according to formula (2), and based on the MATLAB simulation, 93 balanced codes can be selected;

The second step, aiming at the 93 kinds of balanced pseudo random codes selected in the first step, respectively according to the formulas (5), (7) and (9); calculate the autocorrelation side-lobe maximum $\mathrm{x}$, the reciprocal of autocorrelation 
quality factor $y$, and the calculated results are statistically analyzed. The calculation results are shown in figure 2 .

Then it needs to statistically sort the results. The optimization process is as follows:

a. Initialize three parameters, set $\mathrm{x} 0=108$, y0 $=-26.8$, $\mathrm{z} 0=0.95$, combine and extract the codes of which parameters are respectively less than $\mathrm{x} 0, \mathrm{y} 0, \mathrm{z} 0$, then make comparisons with each other;

b. If the three corresponding parameters of one each code are all less than the initial values $\mathrm{x} 0, \mathrm{y} 0, \mathrm{z} 0$, respectively, or the values $y$ and $z$ are less than the initial values $y 0, z 0$, the code should be saved into Num as a new code family;

c. Reset the three parameters, make $\mathrm{x} 0=\mathrm{x} 0+2, \mathrm{y} 0=\mathrm{y} 0$ $+0.5, \mathrm{z} 0=\mathrm{z} 0+0.05$, repeat the step (a) until the number of code in the Num is equal to 24. The specific flow chart is shown in figure 3 .

The third step, according to the formulas (6) and (8), by using the 24 codes selected in the second step, their maximum cross-correlation side-lobe value and the reciprocal of the linear cross-correlation quality factor are calculated. The code is optimized by comparing the value of the two parameters. It can be described as following:

a. Calculate the maximum value of the cross-correlation side-lobes of each code, extract the two codes of maximum and minimum side-lobe values to form a new code set $S$, then select one of the remaining 22 codes randomly, which equals to $c$, after that correlate it respectively with the two codes in $\mathrm{S}$ to obtain $\mathrm{cl}$ and $\mathrm{c} 2$, select the bigger parameters of $\mathrm{c} 1$ and $\mathrm{c} 2$, that is $\max (\mathrm{c} 1, \mathrm{c} 2)$;

b. Take any one of the remaining codes, which equals to $\mathrm{d}$, then correlate it respectively with the two codes in $\mathrm{S}$ to obtain $\mathrm{d} 1$ and $\mathrm{d} 2$, select the larger value of $\mathrm{d} 1$ and $\mathrm{d} 2$, which is $\max (\mathrm{d} 1, \mathrm{~d} 2)$;

c. Compare the larger correlation values respectively obtained in the last two steps. If $\max (\mathrm{c} 1, \mathrm{c} 2)<\max (\mathrm{d} 1, \mathrm{~d} 2)$, the $\mathrm{c}$ code is saved in the new code set Num1, conversely the $\mathrm{d}$ code is saved in the set Num1. The filtering will not finished until Num1=12. The specific flow chart is shown in figure 4 .

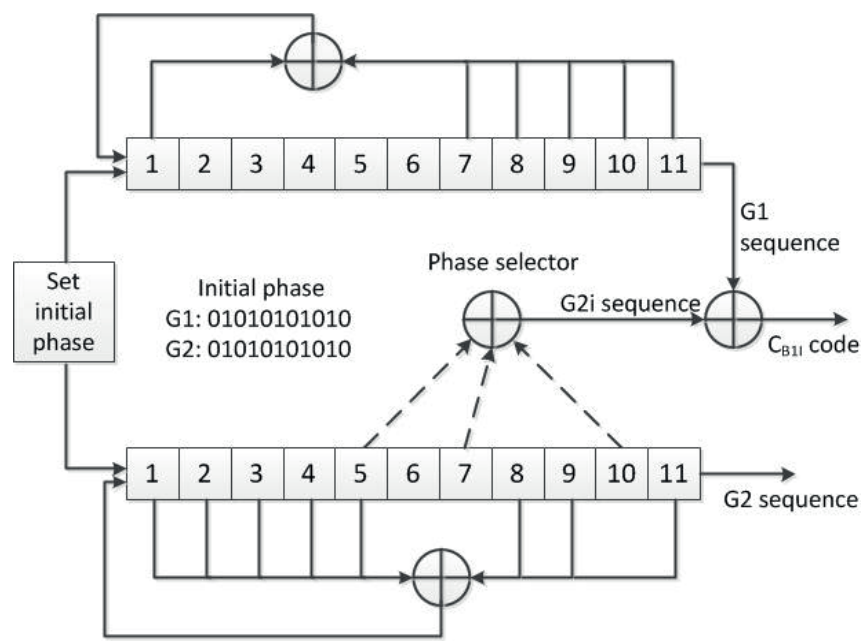

Fig. 1. Schematic diagram of pseudo satellite ranging-codes generator
Based on the three steps above, at last 12 ranging code combinations can be selected. The specific corresponding standard values of every code are shown in Table 2.

\section{PERFORMANCE ANALYSIS OF THE OPTIMIZATION PSEUDOLITE RANGING-CODES}

In Table 2, the ranging-codes of No.4 and No.5 are selected and the chip square wave diagram is shown in Figure 5.
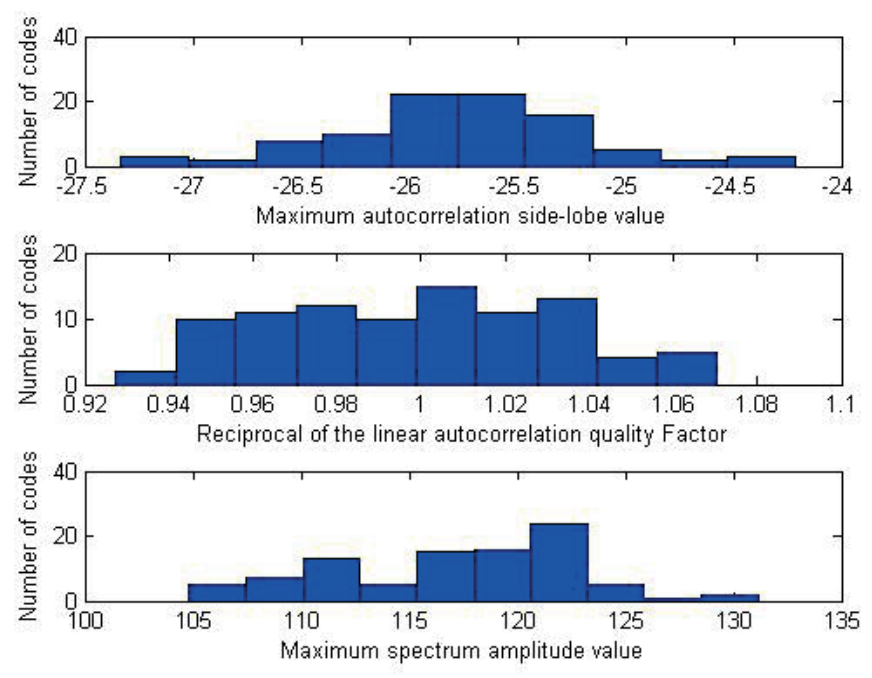

Fig. 2. Statistical results of parameter calculation

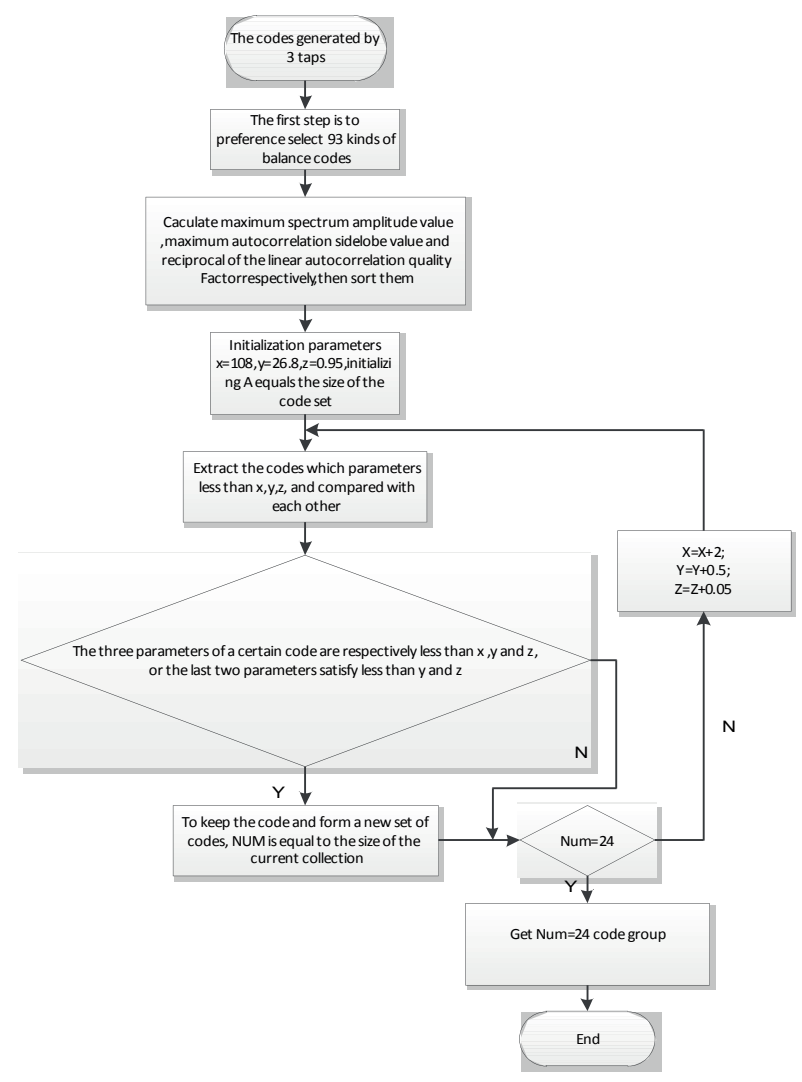

Fig. 3. Second step screening algorithm flowchart 


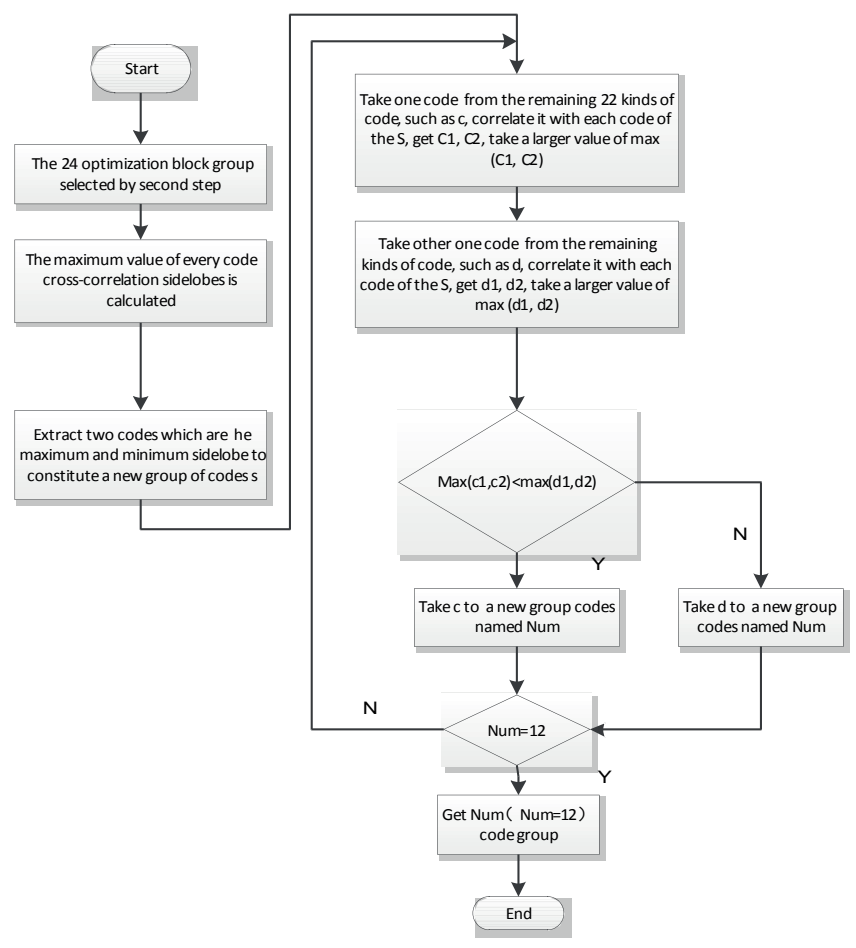

Fig. 4. Third step screening algorithm flowchart

From the left panel of Figure 5, it shows the first 50 codes of No.4 ranging code (the top 30 bits are 11001-11101-1000100000-10001-11000). From the right figure of Figure 5, it shows the first 50 codes of No.5 ranging-codes (the top 30 bits are 11000-10011-00010-00001-00011-01110). It can be seen that the two ranging-codes have orthogonal characteristics and satisfy the design requirements. According to the correlation characteristics, the normalized correlation function curve of the pseudolite No.4 and No.5 ranging-codes is shown in Figure 6. It can be known from Figure 6 that the Beidou pseudolite ranging-codes have good autocorrelation and crosscorrelation characteristics, which can meet the performance requirements of the navigation ranging codes. From the figure we can also know that the correlation peak characteristic is good, which shows that it is possible to successfully capture the Beidou pseudolite No.4 ranging -codes.
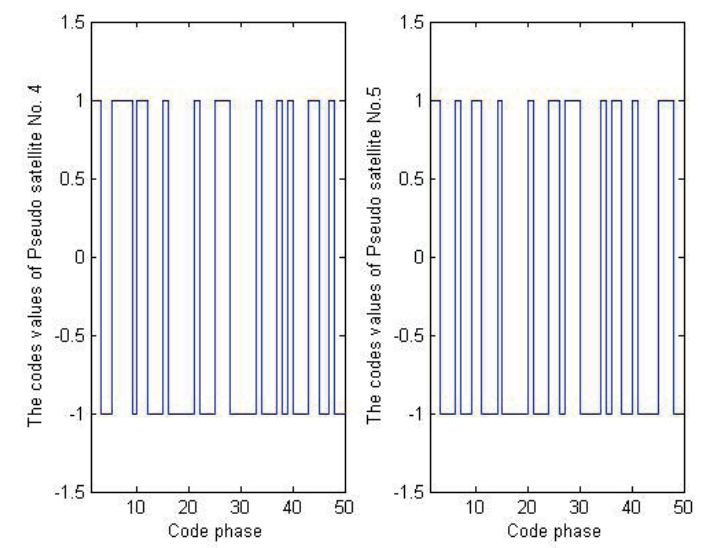

Fig.5. The top 50 bit codes waveform of No.4 and No.5 pseudolite ranging-codes

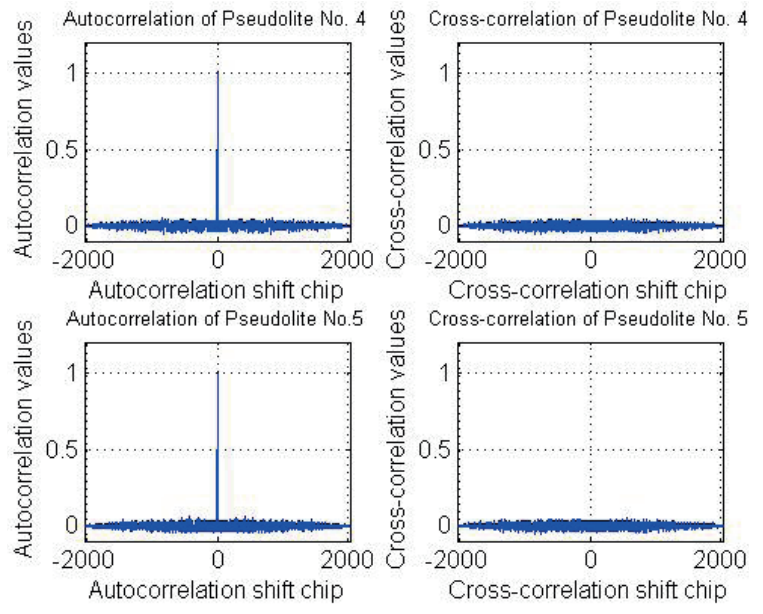

Fig.6. Correlation characteristic of No.4 and No.5 pseudolite ranging-codes

The ranging-codes of pseudolite and satellite belong to the same code space, pseudolite signal when it is transmitted will interfere Beidou satellite navigation signal. Because time division broadcast mode is employed in pseudolite signal transmission, the interference value is directly proportional to the pulse duty cycle (PDC). Based on this, when the pseudolite signal is transmitted, the pulse duty cycle should be minimized; however, the low PDC will lead to the pseudolite signal to fail to be captured and tracked. Therefore, it is necessary to select a suitable PDC in order to modify other receivers. Firstly, the maximum PDC value of the Beidou pseudolite pulse signal should be selected.

(1) Selection of maximum duty cycle

In the interference mode of "pseudo satellite signal + thermal noise", the average signal to noise ratio (SNR) of the satellite signal is reduced, as shown in the formula (10).

$$
\frac{S}{I_{a v g}}=\frac{S}{I+P}
$$

In the Formula, the $S$ stands the power of satellite effective signal, the $I$ is the power of other satellites and thermal noise interference, the $P$ represents the pseudolite interference power. According to the formula (10), the SNR of the navigation satellite signal with different duty cycle in the B1I frequency point can be got, which can be expressed as a formula (11).

$$
\left(\frac{\mathrm{S}}{\mathrm{I}}\right)_{\mathrm{avg}}=10 \log _{10}\left(\frac{\mathrm{S}_{\mathrm{typ}} \cdot(1-\mathrm{d})}{\mathrm{pd}+(1-\mathrm{d})}\right)
$$

Where, $\mathrm{S}_{\text {typ }}=10^{(\mathrm{s} / 1)_{\text {typ }}} \mathrm{p}^{10}, \mathrm{p}=10^{(\mathrm{P} / 1) / 10}$, the $d$ shows PDC. The SNR of pseudolite signal is represented by the formula (12).

$$
\left(\frac{\mathrm{S}}{\mathrm{I}}\right)_{\text {avg }}=10 \log _{10}\left(\frac{\mathrm{S}_{\mathrm{max}} \cdot \mathrm{d}}{\mathrm{p} \cdot\left(\mathrm{N}_{\mathrm{pl}}-1\right) \cdot \mathrm{d}+1-\left(\mathrm{N}_{\mathrm{pl}}-1\right) \cdot \mathrm{d}}\right)
$$


In the Formula, the $S_{\text {max }}$ shows the maximum power available of the user receiver, the $\mathrm{N}_{\mathrm{pl}}$ shows the number of pseudolite. According to the formula (11) and (12), the simulation result is shown in Figure 7.

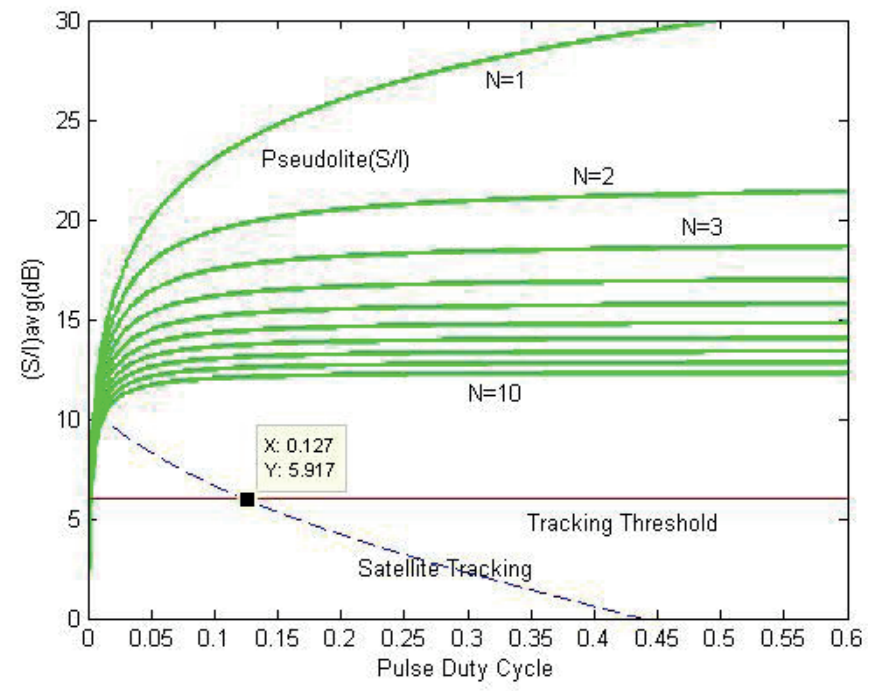

Fig.7. Analysis of pulse signal duty cycle

In the figure 7 , the blue dashed line indicates the signal to noise ratio of the effective satellites signals. The red line indicates the tracking threshold, and the green curve indicates the signal to noise ratio(SNR) distribution condition of the pseudo satellite signals under the condition of different number of satellites. The abscissa of the crossover point which is generated by the red solid line and the blue dashed line is the maximum value of the pseudo satellite pulse signal PDC. As can be seen from the graph, the simulation results show that the maximum duty cycle is $12.7 \%$.

(2)Modulation of pseudo satellite pulse signal

After the maximum duty cycle of the pseudolite pulse signal have been determined, the selection range of duty cycles value is further reduced, and it is also easier to choose the appropriate duty cycle, this provides the necessary premise for the further research of the pulse signal modulation. According to the simulation results, when the number of satellites is equal to 3 , the duty cycle of the pulse signal PDC is equal to $6.25 \%$. When the signal strength of pseudolite does not exceed the satellite signal $30 \mathrm{~dB}$, the Beidou user receiver can work properly. Therefore, for the Beidou satellite C-B1I code, the pseudolite pulse duty cycle can be set to $1 / 16(6.25 \%)$. The cycle of B1I ranging codes is $1 \mathrm{~ms}$, and the length of the code is 2046. According to the value of the duty cycle, the 2046 bit pseudorandom codes of the pseudolite signal can be divided into 16 parts according to the specific chip. In the first 15 milliseconds, 128 bits are sent per milliseconds, and 126 bits are sending in sixteenth millisecond. In this way, one pseudolite signal chip can be completed transmission in $16 \mathrm{~ms}$. Modulation mode of Beidou pseudolite pulse signal is shown as Figure 8.
Beidou pseudolite system uses code division and time division multiplexing method based broadcasting of which the frequency point selection is the same with the Beidou satellite system of which the frequency is $B 1$. The code rate is $2.046 \mathrm{Mcps}$. The pulse duty cycle is $6.25 \%$. The frequency is set as $4.092 \mathrm{MHz}$; the sampling frequency is set as $16.368 \mathrm{MHz}$; the No.4 ranging-codes are selected and the signal-to-noise ratio is set as $-25.14 \mathrm{~dB}$. After down-conversion, the acquisition result using the terminal perception is shown in Figure 9.

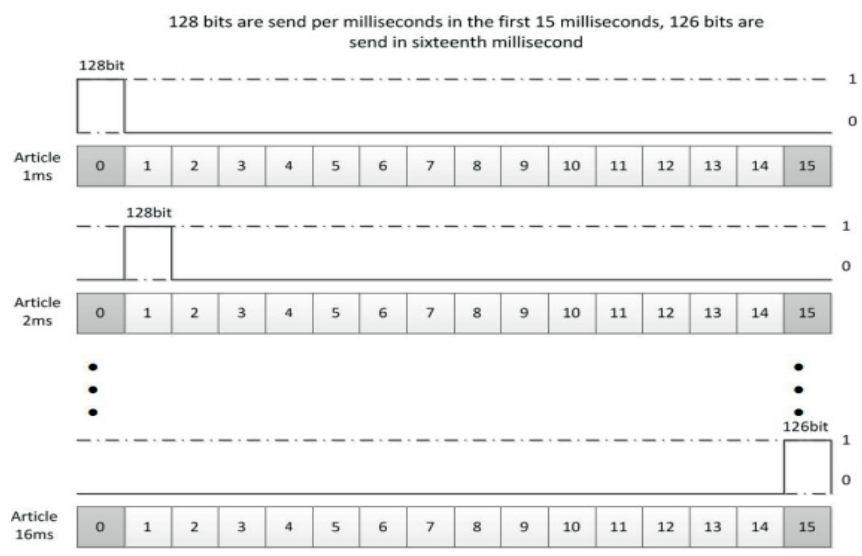

Fig.8. Modulation mode of Beidou pesudolite pulse signal

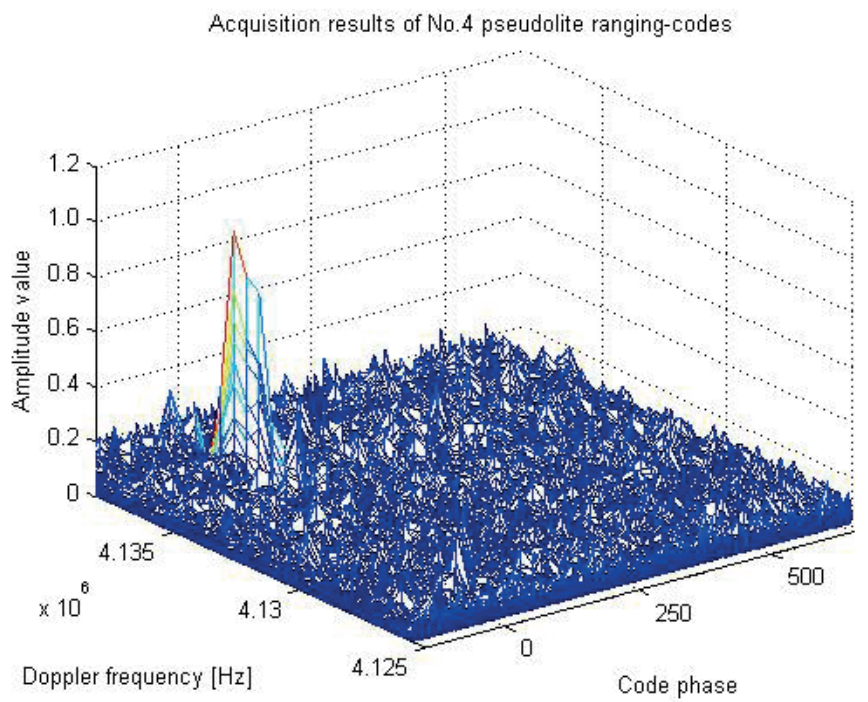

Fig.9. Ranging-codes acquisition results of No.4 pseudolite ranging-codes 
Tab. 2. Beidou pseudolite ranging-codes optimization combination

\begin{tabular}{|c|c|c|c|c|c|c|c|}
\hline $\begin{array}{c}\text { Ranging- } \\
\text { codes } \\
\text { number }\end{array}$ & $\begin{array}{c}\text { G2 taps } \\
\text { selection }\end{array}$ & $\begin{array}{c}\text { Codes } \\
\text { delay } \\
\text { phase / } \\
\text { chips }\end{array}$ & $\begin{array}{c}\text { Autocorrelation side- } \\
\text { lobe maximum /dB }\end{array}$ & $\begin{array}{c}\text { Reciprocal of the linear } \\
\text { autocorrelation quality } \\
\text { Factor }\end{array}$ & $\begin{array}{c}\text { Maximum } \\
\text { spectrum } \\
\text { amplitude }\end{array}$ & $\begin{array}{c}\text { Cross-correlation side- } \\
\text { lobe maximum /dB } \\
\text { the linear cross- } \\
\text { correlation quality } \\
\text { Factor }\end{array}$ \\
\hline 1 & $3 \oplus 4 \oplus 5$ & 1228 & -26.6679 & 0.9693 & 116.2667 & 1.0331 \\
\hline 2 & $3 \oplus 4 \oplus 6$ & 760 & -26.1359 & 1.0090 & 111.7251 & -24.3539 \\
\hline 3 & $1 \oplus 5 \oplus 9$ & 796 & -26.3978 & 1.0372 & 111.0172 & -24.6387 \\
\hline 4 & $1 \oplus 3 \oplus 8$ & 26 & -26.4869 & 1.0412 & 114.2188 & -23.9435 \\
\hline 5 & $1 \oplus 4 \oplus 5$ & 615 & -26.0504 & 1.0086 & 106.5294 & -24.2149 \\
\hline 6 & $1 \oplus 8 \oplus 11$ & 246 & -26.3097 & 1.0203 & 109.9418 & -24.2842 \\
\hline 7 & $1 \oplus 6 \oplus 9$ & 1362 & -26.1359 & 1.0281 & 109.8262 & -24.2149 \\
\hline 8 & $2 \oplus 7 \oplus 10$ & 1361 & -25.8817 & 1.0137 & 104.8326 & -24.2841 \\
\hline 9 & $1 \oplus 3 \oplus 9$ & 1653 & -25.1608 & 0.9626 & 114.5480 & -24.3539 \\
\hline 10 & $1 \oplus 3 \oplus 5$ & 403 & -25.1608 & 0.9987 & 1.0350 \\
\hline 11 & $1 \oplus 4 \oplus 9$ & 1178 & -25.2380 & 0.9692 & 111.0172 & -24.2842 \\
\hline 12 & $2 \oplus 6 \oplus 7$ & 1981 & -25.4738 & 1.0327 & -24.2149 \\
\hline
\end{tabular}

\section{CONCLUSION}

In this paper, according to the design requirements of the Beidou navigation signal ranging codes, the generation scheme of Beidou pseudolite ranging-codes are proposed. The phase offset selection and optimization selection methods of the ranging-codes generator are analyzed in details. A correlate all 3 taps combinations are obtained by using the scheme, and the optimal combination are selected according to the parameters. Finally, 12 kinds of Beidou pseudolite ranging-codes combinations are obtained, and the performance of the optimal codes are analyzed and verified. From the simulation results, it can be seen that the designs of the ranging-codes have good balance and correlation and can be normally captured to meet the performance requirements of the navigation pseudo random spreading codes. Therefore, it can be used as pseudolite ranging- codes.

\section{ACKNOWLEDGEMENTS}

This project is partially supported by the National 863 Plan of China (2013AA122403).

\section{BIBLIOGRAPHY}

1. Ji L, Shan Q: The Development Outline and Latest Evolution of Global Navigation Satellite System. GNSS World of China, Vol. 37, no. 5, pp. 56-61, 2012.

2. Dong S: The Compass Time System and Its Interoperation. APPLIED MECHANICS AND MATERIALS, Vol. 239, pp. $548-551,2012$.

3. Sun F, Liu S, Zhu X: Research and Progress of Beidou Satellite Navigation System. Sciece China: Information Sciences, Vol. 55, no. 12, pp. 2899-2907, 2012.
4. Yang C, Lu X, Wang X: Performance Analysis for Ranging Codes of Satellite Navigation System. Journal of Time and Frequency, Vol. 36, no. 3, pp. 173-180, 2013.

5. TANG J: Developing and Applying Analysis of BeiDou Navigation Satellites Regional System. Global Positioning System, Vol. 38, no. 5, pp. 47-52, 2013.

6. Montenbruck O, Hauschild A, Steigenberger P, Hugentobler U, Teunissen Pand Nakamura S: Initial assessment of the COMPASS/ BeiDou-2 regional navigation satellite system. GPS Solutions, Vol. 17, no. 2, pp. 211-222, 2012.

7. Wu T, Zhang Y, Liu Y: BD/GPS integrated positioning method. Remote Sensing, Vol. 5, pp. 1087-1097, 2014.

8. WANG X, FAN A, FU Z: The Design of BeiDou Pseudo-satellite Compatible Receiver. Wuhan: China Satellite Navigation Conference, 2013.

9. Liu D, BO Y, WU P: The Research on DOP of Beidou Positioning System Using Pseudolite. Fire Control \& Command Control. Vol. 34, no. 7, pp. 137-139, 2009.

10. Hikawa H: Frequency-based multilayer neural network with on-chip learning and enhanced neuron characteristics. IEEE Transactions on Neural Networks, Vol. 10, no. 3, pp. 545-53, 1995.

11. Serpen G, Gao Z: Complexity Analysis of Multilayer Perceptron Neural Network Embedded into a Wireless Sensor Network. Procedia Computer Science, Vol. 36, pp.192-197, 2014.

12. Kumar A, Joshi H, P. S: Neural Network Approach for Automatic Landuse Classification of Satellite Images: One-Against-Rest and Multi-Class Classifiers. International Journal of Computer Applications, pp.134, 2016. 
13. Raza M Q, Khosravi A: A review on artificial intelligence based load demand forecasting techniques for smart grid and buildings. Renewable \& Sustainable Energy Reviews, Vol. 50, pp.1352-1372, 2015.

14. Hosseini S M S, Maleki A, Gholamian M R: Cluster analysis using data mining approach to develop CRM methodology to assess the customer loyalty. Expert Systems with Applications, Vol. 37, no. 7, pp.5259-5264, 2010.

15. Liu Y F, Li M Y: Application of Data Mining Technology in CRM. Applied Mechanics \& Materials, Vol. 513, pp. 2103-2106, 2014.

16. Maheswari R U, Mahesan S S: Role of Data Mining in CRM. International Journal of Engineering Research, Vol. 3, no. 2, pp. $75-78,2014$

\section{CONTACT WITH AUTHOR}

\section{Deliang Su}

e-mail:sdl7811@whut.edu.cn tel.: 13093212998

School of Information Engineering Wuhan University of Technology,

Wuhan Hubei

430074

\section{China}

